\title{
Process validation: coping with three dilemmas in process-based single-case research
}

\author{
Poul Houman Andersen \\ Department of Business and Economics, Aalborg University, Aalborg, Denmark and \\ NTNU Fakultet for Ingeniorvitenskap og Teknologi Trondheim, Trondheim, Norway \\ Anna Dubois \\ Chalmers Tekniska Hogskola, Gotebord, Sweden, and \\ Frida Lind \\ Department of Technology Management, Chalmers University of Technology, Gothenburg, Sweden
}

\begin{abstract}
Purpose - Recent research suggests that the interest in process-based single-case studies is increasing in business-to-business (B2B) marketing. This paper aims to discuss research validity issues and dilemmas encountered by process-based single-case researchers in B2B marketing.

Design/methodology/approach - This is a methodology paper that builds on an integration of experiences, ideas and literature.

Findings - In the paper, three dilemmas are suggested that researchers need to deal with in process-based single-case research. These relate to the casing process: crafting the case, communicating the case and describing the process of the study. Furthermore, process validation is suggested as a research quality concept concerned with how these dilemmas are handled.

Research limitations implications - Based on the notion of process validation, the authors provide suggestions for how casing, as a processbased single-case approach, can be conveyed and advanced in its own right.

Practical implications - This study can be used to convey insights that can help new and experienced researchers in conducting single-case studies in B2B.

Originality/value - Coping with issues of research quality in B2B marketing is of relevance to researchers dealing with process-based single-case research and process validation issues, as well as to journal reviewers evaluating the qualities of process-based single-case research.
\end{abstract}

Keywords Qualitative research, Business-to-business marketing, Process validation, Quality criteria, Single-case research

Paper type Technical paper

\section{Introduction}

There is an increasing interest in case studies of processes in business marketing (Halinen and Törnroos, 2005; Halinen et al., 2012; Dubois and Gadde, 2014). There are several good reasons for this. Business markets are featured by ambiguity, fuzzy boundaries and continuous change, and the research methodologies issued by researchers have to adjust to reflect an unfolding and changing reality (Bonoma, 1985; Langley, 1999; Gummesson, 2001). Also, consumer marketing increasingly encompasses process-based approaches to understanding marketing phenomena (for recent examples, Giesler and Thompson, 2016).

Case research is recognized as a well-suited approach in efforts to describe and understand business marketing processes (Halinen and Törnroos, 2005) and for exposing both agency and structure in network and business interactions (Nicholson et al., 2014). In a business marketing context, a case study can be understood as:

The current issue and full text archive of this journal is available on Emerald Insight at: www.emeraldinsight.com/0885-8624.htm

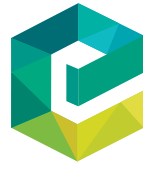

Journal of Business \& Industrial Marketing 33/4 (2018) 539-549

Emerald Publishing Limited [ISSN 0885-8624] [DOI 10.1108/JBIM-07-2016-0152]
A research method that involves investigating one or a small number of social entities or situations about which data are collected using multiple sources of data and developing a holistic description through an interactive research process (Easton, 2010, p. 119).

Moreover, Easton argues that the popularity of using case research to study business marketing phenomena can be explained by the nature of the subject; "The main units of analysis are organizations and relationships, which are difficult to access, and complex in structure in comparison with, for example, consumer markets" (ibid., p. 118).

In this paper, we will focus on process-based single-case research as an approach that provides unique opportunities for understanding possible configurations of an underlying social reality (Tsoukas, 1989; Dyer and Wilkins, 1991; Dubois and

(C) Poul Houman Andersen, Anna Dubois and Frida Lind. Published in the Fournal of Business $\mathcal{E}$ Industrial Marketing. Published by Emerald Publishing Limited. This article is published under the Creative Commons Attribution (CC BY 4.0) licence. Anyone may reproduce, distribute, translate and create derivative works of this article (for both commercial and non-commercial purposes), subject to full attribution to the original publication and authors. The full terms of this licence may be seen at http://creativecommons.org/licences/by/4.0/legalcode

Received 14 July 2016

Revised 29 May 2017

18 July 2017

13 December 2017

Accepted 19 December 2017 
Gadde, 2014). In contrast to this approach, the dominant research methodology literature on case research in businessto-business (B2B) favors multiple-case research, following a disciplinary convention rooted in a variance-based approach (Piekkari et al., 2009, 2010). Multiple-case studies are recommended in marketing research to reach "theoretical saturation" or "maximum variation" (Perry, 1998). In a conventional multiple-case study design, the underlying notion is to sample case exemplars based on known theoretical constructs and a clearly formulated research question. Variance-based methods provide explanations based on efficient causation, where independent variables impact on the dependent variable (Van De Ven and Poole, 2005). According to Eisenhardt (1989, p. 339):

The concept of a population is crucial, because the population defines the set of entities from which the research sample is to be drawn. Also, selection of an appropriate population controls extraneous variation and helps to define the limits for generalizing the findings.

Apparently, the conventional variance-based multiple-case approach and the process-based single-case approach have different qualities (for a further discussion on variance versus process approaches, see Mohr, 1982; Langley, 1999). Processbased approaches account for temporal connections between events and may transgress between levels and units of analysis in the search for formative patterns and cycles. In process theories, the basis for explanation is the ordering and sequences of events leading up to an event, rather than ordered dependent and independent variables. The process-based single-case approach gives primacy to unfolding sequences over steady states. Social subjects, such as an exchange relationship in business marketing, assume a much feebler existence, given that other actions and interactions may change, counter or dissolve what researchers recognize as belonging to phenomena such as a "relationship". According to Langley et al. (2013, p. 1): "Process research thus focuses empirically on evolving phenomena and it draws on theorizing that explicitly incorporates temporal progressions of activities as elements of explanation and understanding." Thus, when embarking on process designs, we draw on a different understanding of what knowledge is and what quality criteria must be met with respect to producing valid insights (Van de Ven, 2007) [1].

Central to the differences between variance- and processbased research designs is the notion of validity. In discussions about qualitative approaches to research, such as case-based research, validity is increasingly used as a measure to discuss whether researchers see what they think they are seeing (Silverman, 2000). In most discussions, validity is discussed as a way to (dis)qualify research results and their reliability when designing studies and communicating findings to others. In process-based research, a particular issue arises around the ongoing interaction in the research context and the ongoing validation process of the research activities (Andersen and Skaates, 2004). Therefore, we will suggest and discuss process validation as a concept to assess how well a process-based single-case study copes with particular dilemmas that researchers encounter as the research process unfolds. As a consequence, process validation relates both to the process itself and to the outcome.

This paper seeks to accomplish two aims. The first is to identify and elaborate on validity issues relating to process- based single-case research by combining existing sources into a synthesis (Corley and Gioia, 2011). The contribution accentuates process validation as a quality measure for processbased single-case research in business marketing. The second aim is to identify and elaborate on three dilemmas that are salient to ensure process validation in case-based research. Our ambition is not to script process-based single-case research, as this basically defies the explorative nature of the research journey. Instead, the authors have learned during their own research efforts, as well as by listening to and reading about others' efforts, that there are commonalities when it comes to maintaining reflexivity and openness when engaging in processbased case research. By integrating ideas, suggestions and experiences, useful guidance can hopefully be provided for aspiring and weathered researchers dealing with process validation issues and for journal reviewers when evaluating the qualities of process-based single-case research.

The paper is structured as follows: we start by discussing the role of process-based single-case research in business marketing and link process-based case research to general discussions of validity in relation to case research introducing the concept of process validation. Based on this concept, we outline three dilemmas that relate to the case researchers' task of ensuring process validation. These dilemmas concern crafting the case, communicating the case and describing the process of the study. In the concluding discussion, we draw implications for research, with a specific view on authors and reviewers.

\section{Process-based single-case research in business marketing}

Process-based single-case research has played a key role in the development of research on business marketing and purchasing phenomena (Dubois and Araujo, 2004; Dubois and Araujo, 2007; Easton, 2010). According to Easton (1995, p. 480):

Because of the richness of the picture produced by case research, the approach is suitable to handle the complexity of network links amongst actors and can be used to trace the development of network changes over time.

As process-based single-case studies permit researchers to capture the ongoing interaction among actors in the development of industrial networks, it has received widespread application.

A notion of time and how it influences processes is central for studying interaction. Understanding how time links to interactions in B2B marketing has been discussed by Medlin (2004). He addresses three time-related issues that are important for process-based approaches to case studies. First, for humans, time measures the separateness of events and is important for the identification of an event and for ordering and understanding sequences of events. Second, time has a boundary function for human cognition. Events happen in a certain period of time, and time binds things together (events happening at the same time). Finally, time is an important notifier for processes as it provides a context: events may have happened in the past or take place in the future. The future and the past are always moving and are helping to define or provide sense in the understanding of the present. All three time-related issues are important to consider in process-based single-case studies. 
Recent research in B2B marketing provides several examples of process-based single-case studies. For example, Storbacka and Nenonen (2015) expand previous notions of "market learning", from organizational learning to inter-organizational learning, by using a longitudinal single-case study. Another example is Guenzi and Storbacka (2015), who study how a multinational company adopted a key account management program and, based on this study, develop "a comprehensive understanding of organizational issues that firms need to consider when implementing a KAM program" (ibid., p. 84). Faes and Matthyssens (2009) analyze the process of changing sourcing strategy and point to the importance of dynamism in the context of finding reasons for those changes. Wu et al. (2016) study selection processes in open innovation. In both examples, the sequencing and separateness of events are important building bricks for establishing a sequenced order, helping to establish a narrative.

Looking at recent studies of innovation in B2B networks, there are also many examples of single-case studies that capture those phenomena in depth in their context (Munksgaard, 2015; Lind, 2015). For instance, Perna et al. (2015) explore the connection between innovation and its "monetary dimension" in a single-case study of an innovation process involving a new type of thin-film solar cells and use the process perspective in identifying key connections between social-material resources and the monetary dimension.

Single-case research concerns a holistic rather than an atomistic approach to a phenomenon, as it tries to frame and set the boundaries around aspects relevant to the case and focus on both actors and the contexts they inhabit. Referring back to Medlin's time categories, time fulfills an important role as a boundary for the study. A time context in terms of a past and a future is critical for understanding exogenous events, for instance, when studying processes of relationship endings (Tähtinen and Vaaland, 2006). Reality is a contested concept, as researchers' attempts to understand the complexity of a context are limited not only by their mental faculties but also by observations being theory-laden and embedded in language (Tsoukas, 2005; Easton, 2010). Nonetheless, the concept is used for describing attempts to model some aspects of the "real" world. Studies in business marketing, seeking to understand complex interaction patterns among actors within or across organizational boundaries, require learning efforts that may change the researchers' perspective on the studied phenomenon. Consequently, in studies following the process logic, the theories and concepts that initially made sense for grasping the qualities of a phenomenon tend to change as B2B researchers explore and learn more about the context they study (Bizzi and Langley, 2012; Halinen et al., 2013).

A process-based single-case study permits inquiry into the nature of a phenomenon in a single case. During the study process, a single-case approach permits researchers to reconsider their initial assumptions about the nature of the phenomenon (Dubois and Gadde, 2002). Time is an important aspect for creating a conceptual boundary and thus describe what a case is a case of (Ragin, 1992). As time-bound boundaries change, so does the locus of the case. Hence, the aim is to not hold on to the initial conceptualizations pertaining to the subject of the study - which is necessary in multiple-case studies - but to develop them. In a process-based single-case study, the casing process, during which the case emerges, is characterized by the researcher constantly asking what the case is a case of. This feature clearly distinguishes single from multiple-case approaches (Dubois and Gadde, 2014).

The characteristics of process-based single-case research in business marketing are not, however, echoed in an equally strong rooting of practice in the conventions in methodological literature on case-based research (Piekkari et al., 2010). In several studies of case research practices, there is a striking lack of declaration in the methodological sections with respect to explaining how the case study processes were carried out and how the researchers iterated between field-based observations and theory (Piekkari et al., 2009, 2010). Moreover, the lack of a shared notion of research quality for evaluating the rigor of qualitative research is particularly challenging for single-case researchers engaged in studies of processes.

\section{The concept of validity under different philosophical assumptions}

Central to the issue of rigor and quality in research is the notion of validity. Validity has to do with truth, rigor and value of research or, in short, the quality of the research. It is an ideal state to be pursued as an integral part of doing research, rather than a commodity to be purchased by applying a sufficient number of checkpoints (Brinberg and McGrath, 1985). It is therefore important to consider how this concept is understood and how it relates to process-based single-case research. Case study research offers different perspectives on ensuring rigor in qualitative research, based on the epistemological stance of the researcher. An overview of different research paradigms and their approaches to quality criteria for case study research is offered by Healy and Perry (2000); see Table I. In the field of business marketing, the complexity of business relationships and networks has inspired many case researchers to rely on critical realism (Easton, 1995, 2010; Ryan et al., 2012).

Following the positivist research tradition, which dominates case-based research within business marketing, validity has come to mean the correspondence between empirical "facts" (evidence) and theoretical constructs (Perry, 2000; Riege, 2003). Three forms of validity criteria are often used (Beverland and Lindgreen, 2010): construct validity, securing that correct operational measures have been established for the concepts in use; internal validity, making sure that proper causal relationships have been established; and external validity, proving that the domain to which a study's findings belong can be generalized. However, the combination of these validity criteria has been found to be difficult (Bonoma, 1985; Dubois and Gadde, 2014). For instance, Bonoma (1985) points to the trade-off that has to be made between internal validity, or "data integrity", and external validity, as the closer the researcher gets to the subject of the study, the more difficult it becomes to compare data across categories.

In sum, process-based single-case studies fit best with subjective ontologies, such as realism and constructivism. Critical realism and constructivism both relax the claim for an objectivist epistemology. Although there are clear ontological differences between critical realism and constructivism (for a further elaboration on philosophical orientations and case research, see Easton, 1995), we believe that for a process-based single-case researcher seeking to ensure rigor and quality, there 
Table I Quality criteria for case study research within the realism, positivism and constructionism paradigms

\begin{tabular}{|c|c|c|c|}
\hline Paradigm/Element & Positivism & Realism & Constructivism \\
\hline Ontology & Reality is real and apprehendable & $\begin{array}{l}\text { Reality is real but only imperfectly and } \\
\text { probabilistically apprehendable }\end{array}$ & $\begin{array}{l}\text { Multiple, local and specific } \\
\text { "constructed" realities }\end{array}$ \\
\hline Epistemology & Objectivist: findings are true & Modified objectivist: findings are probably true & Subjectivist: created findings \\
\hline Quality criteria & Reliability, external and internal validity & Analytical generalization & Trustworthiness \\
\hline
\end{tabular}

is more uniting than dividing these paradigms with respect to understanding complex processes of actors interacting in and with a specific context. In this assumption, we are not alone. Kwan and Tsang (2001) argue that although there are differences between the constructivist and the critical realist's core assumptions, their epistemologies differ more in degree than kind. In process-based single-case research, a certain kind of "bias," "contamination" or "co-theorizing" (Michailova et al., 2014) should be embraced as a way to gain the contextualist's perspective ingrained in the study, because direct observation and interaction provide insights that are not possible from a distance. Deep involvement combined with broad theoretical lenses breeds diversity of insights and leads researchers to develop a broader pool of convincing stories to select from when presenting findings (Andersen and Kragh, 2010). As pointed out by a quantitative researcher such as Campbell (1975), case-based research may provide messy data, but it is a price that must be paid for deepness in observation (Bansal and Corey 2012 for a similar point). Because no one enters a research site without some idea of what to find, there is no such thing as an objective mind when conducting qualitative research and when there is interaction with subjects. Glaser and Strauss point this out well (1967, p. 253):

No sociologist can possibly erase from his mind all the theory he knows before he begins his research. Indeed the trick is to line up what one takes as theoretically possible.

\section{Validation and process-based single-case studies}

In process-based single-case studies, the positivistic validity criteria are problematic. First, these validity criteria rely on the meanings of theoretical constructs being kept constant during a study and being understood in a common shared way by all researchers in the research community. Second, the empirical data to be "collected" in a study are assumed to be pre-defined in relation to the study. Hence, according to the positivist notion of validity, the matching of theoretical constructs and empirical observations is a static aspect of research, i.e. something that is not related to the process of study but only to the result of it. The result, in turn, assumes a direct relation to predetermined decisions regarding what theory to match with what empirical data, and the quality thus relates to how successful this match turns out to be (Dubois and Gadde, 2002). In contrast, the validity in single-case research, as the correspondence between theoretical constructs and empirical observations, is embedded in the research process and thus also subject to change during the whole process of study. Therefore, neither the set of constructs used (nor their exact meaning) nor the empirical data, based on which validity claims are to be made, are fixed or exactly defined before the ending of the study.
In process-based single-case research, interaction with the empirical domain unfolds over time, and as the researcher learns more about the actors and the contexts in which they interact, he/she becomes influenced by these actors, their interactions and their contexts. This involves both context- and boundary-related aspects. Time involves both the boundary setting of the case and what is to be considered parts of the past and the future of the studied process. This immersion in the field is part of the specific value attributed to single-case research (Dyer and Wilkins, 1991). This also means that case selection criteria that may have been important in the initial stages of research are altered as the researcher untangles the case and a more profound understanding emerges. Clearly, based on their findings, researchers will therefore also cherrypick the criteria that lend support to, and illustration of, their observations. In the same manner, refuting the idea of an objective and distanced researcher, Mishler (1990) defines validation as a process through which trustworthiness of observations and interpretations is evaluated. Using the concept of validation instead of validity in process research makes good sense, as it addresses the active role and agency of researchers. Validation highlights researchers as active in building and changing assertions about their research context as they traverse the research field. Researchers are biased in their selection and evaluation of what counts as relevant and irrelevant when conducting research (East, 2016). To ensure process validation, researchers must remain responsive and able to constantly question, check and challenge their emerging findings as they start to materialize in their minds during the research process (Kvale, 1997). However, although there is advice to be found on these matters in the literature, it is not combined with or linked to the context of studying business marketing processes.

Hence, a process-based single-case study can capture and suggest explanations for interdependencies and interactions within a particular context by the use of "received" theory, i.e. grounding the study theoretically. Single-case researchers need to make use of this uniqueness by crafting the case and matching it to the emerging theoretical framework. This is carried out in order to make sense of the empirical data and develop theory. Developing theory based on single-case research provides the researcher with rich opportunities to ground the meaning of concepts in empirical observation and description. However, this strength is directly connected to the potential weakness of making the theory too case specific (Marvasti, 2013). Dealing with the specificity of the case in relation to the analytical generalizability that can be achieved by relating the findings to received conceptual definitions and meanings is thus a challenge. Langley et al. (2013, p. 8) refer to this critical part of theory building as "to climb the ladder of 
abstraction by inferring the general theoretical phenomenon of which the observed particular is a part". Theoretical or analytical generalization is a key aspect of single casing and places high demands on the researcher to demonstrate how the developed theory is grounded both in empirical observation and in "received" theory. We suggest that the strength of this grounding, both with regard to how it is achieved (i.e. the process of the study) and the outcome of the grounding (i.e. the resulting theory development), can be captured by the process validation concept.

\section{Three dilemmas in the validation of process- based single-case research}

Based on the notion that validation for single-case research is about matching theory and empirical observation and that this matching is dynamic and ongoing, we need to see process validation as an integral and ongoing part of conducting process-based single-case studies. To this end, we identify three particular issues with which the single-case researcher has to cope and suggest three dilemmas relating to these issues. Pointing to these issues as dilemmas differs from, for instance, Riege (2003) and Yin (2014) in their search for a design or blueprint for conducting and writing up single-case studies. Such an approach is not useful in process-based case research. Rather than a recipe, and more in alignment with the notion of a journey into an unknown territory, an operative overview is offered of the dilemmas the researcher faces when conducting and validating process-based single-case research.

Taking a starting point in our own experiences of conducting process-based single-case research in business marketing and related fields, a set of themes were initially developed. These themes have been presented at research seminars and conferences and further discussed with researchers within the field of business marketing. The feedback received was used iteratively to revise, further refine and extract a common description and understanding of the process validation dilemmas researchers face during their field studies. The metaphor of a dilemma is preferred because all issues contain an element of reconciling interests and priorities that may oppose each other, and researchers must negotiate their own way in each case. It is contended that single-case researchers will be challenged by these three dilemmas in some form at some point in their research. However, the manifestation of these dilemmas will take on different forms in each project, as will the strategies for dealing with the resulting tensions. In the following sub-sections, we describe and discuss the three identified issues and dilemmas.

\section{Crafting the case - casing}

Process-based single-case research permits interaction between theory and empirical data. In 1992, Ragin introduced "casing" as the activity of transforming empirical material into a meaningful case, encouraging case researchers to constantly ask: "What is the case a case of?" Developing empirical data into a case is suggested to be a (casing) process, and therefore, cases "must be found because they cannot be specified beforehand" (Ragin, 1992, p. 220). Ragin (1992) is also clear about the primary goal for researchers being to link the empirical and the theoretical and that casing is essential in the process of forming meaningful descriptions of the empirical reality. In a similar vein, Dubois and Gadde (2002) suggest "systematic combining" as the process of interaction between theory and empirical data and describe it as a nonlinear and path-dependent process. Theory cannot be understood without empirical observations, and the empirical observations cannot be understood without theory. The goal is matching of theory and reality, and matching is "about going back and forth between framework, data sources and analysis" (ibid., p. 556).

Systematic combining is described as a process involving a number of "directions" and "redirections", which are necessary to achieve matching between theory and empirical data. "Directions" relate to phases in the process wherein the current theoretical ideas guide the data collection, while "redirections" are spurred by changes of different kinds, e.g. regarding the meaning and choice of theoretical concepts and what additional data are needed in adjusting to such modifications of theoretical ideas, or regarding effects of "following the data", or story, if this takes "new" directions (Dubois and Gadde, 2002). Most of these redirections require choices or decisions to be made, for example, with regard to how to expand the empirical study in time and/or scope and how to (re)focus with regard to theoretical framing. Some choices are always made ex ante which may resemble other research approaches, while other choices are made during the research process based on the situation of the researcher and the case study at that time. In making those choices, the context of the researcher plays a role as the researcher interacts with other researchers in the casing process. As a result, the research idea is subject to development throughout the study as an effect of learning and the emergent features of the case itself - both the empirical aspects of it and the way it evolves as a result of a growing theoretical understanding from the perspective of the researcher. Hence, the starting point, as articulated in the initial research "plan" for a single-case study, may not be of particular relevance at the end of the study.

Utilizing the "flexibility" of single-case research in this regard is in conflict with positivist research ideals. For instance, Yin (2014, p. 53) discusses it as a "potential vulnerability" of the single-case design that the case may not be a case of what it was thought to be at the outset. In single-case research based on "casing" or "systematic combining", the research idea is subject to development throughout the study as an effect of learning and the emergent features of the case itself - both the empirical aspects of it and the way it evolves as a result of a growing theoretical understanding of the research phenomenon from the perspective of the researcher. Hence, the starting point articulated as initial research ideas for a single-case study may not be of any particular relevance to the reader of the eventual case. Process-based single-case research can thus be seen as having an "arbitrary starting point" in initial research ideas involving certain theoretical concepts and entry points in a case "to be" (Dubois and Araujo, 2004, p. 210). Michailova et al. (2014, p. 140) see the ending or the exiting in a similar manner: "the question of when to exit can only be answered arbitrarily".

Hence, not only the beginning but also the ending of a case study can be considered as "arbitrary" in some sense as a result of the redirections made in the casing process. Expanding the boundaries of a case in one or several directions, e.g. in time or scope of the network, always has consequences for the theory 
developed (Dubois and Gadde, 2002; Halinen and Törnroos, 2005). How to handle the study in relation to the "issue of arbitrariness" is therefore something the researcher has do deal with when publishing the result of single-case research.

The dilemma when it comes to single-case research in view of the nature of the casing process relates to how the issue of arbitrariness is handled by the researcher. In accordance with traditional positivistic research ideals, it may be tempting not to deal with the emergent needs to redirect a case study but instead to "settle" for the current "findings", even though the researcher has come to realize that the initial assumptions and research ideas were all "wrong". At the other end, the researcher may take the arbitrariness too far by not daring to suggest any conclusions and instead suggesting continued research and expansion of the study in every direction identified as potentially interesting.

Single-case researchers who try (or are forced) to follow conventions tend to deal with this dilemma either by arguing for having achieved "theoretical saturation" (Glaser and Strauss, 1967) or by ex post rationalizations. Typically, when reviewers cannot find explicit accounts of clearly articulated (ex ante) research questions or propositions (Yin, 2014), they often ask for clarification. Some may see the lack of a precise research question as a sign of insufficient rigor on behalf of the researcher and warrant their rejection of the paper based on missing research questions. However, when reporting findings from an open-ended single-case study, the interesting result to report back may in fact be the formulation of a specific and surprising research question that challenges conventional beliefs and denies assumptions of audiences (Davis, 1971).

\section{Communicating the case}

How the case is reported is also an issue that requires balancing of conflicting concerns. One of the features of process-based single-case research is the richness of data that can be achieved. However, this richness can also be a burden, as the journal format does not provide much room for detail. Most single-case researchers feel constrained by the limited space available. The case presentation requires selectivity and an ability to structure the selected parts into a convincing story or narrative. Singlecase researchers must negotiate this dilemma in the best way possible. As single case-based papers are primarily read and are remembered for their convincing stories (Dyer and Wilkins, 1991). Therefore, structuring around the story to be told could be considered more important than seeking to fit into a particular format.

Gummesson (2001) points out that all research has an element of interpretation, and that this element assumes a researcher actively selecting and crafting a narrative from data. Moreover, abductive researchers have coined a concept known as the inference to the best explanation. According to this notion, it is up to the researcher to select and present the most convincing story line (Ketokivi and Mantere, 2010; Morgan, 1983). This is also emphasized by Flyvbjerg (2006, p. 238) in his reasoning on writing up a case study: "I tell the story in its diversity, allowing the story to unfold from the many-sided, complex, and sometimes conflicting stories that the actors in the case have told me".

Single-case researchers also run the risk of including too much information and/or detail. As a consequence, it becomes difficult to prioritize and versionalize which issues concern or interest the audience they seek to reach. The dilemma concerned with communicating the case clearly has to do with relating the case insights to what researchers and practitioners find relevant and topical. This often has to go beyond simply stating that the case in question presents another example of what is talked about in the particular conversation and toward making a case for how the story broadens or changes the ongoing conversation. A related concern is how involved or connected the researchers are within the empirical domain and the researchers' ability to distance themselves from the empirical setting to theorize, referred to as a dual state of connect and disconnect (Michailova et al., 2014). Mintzberg (2005, p. 365) formulates this dilemma as: "Too connected, and you risk getting co-opted by the phenomenon. [...] But too disconnected and you cannot develop interesting theory either".

Hence, the reporting of the case is an issue that requires balancing between the detailed and the superficial. This dilemma can be considered a matter of selectivity in view of the richness of data in single-case research. While richness and complexity are indeed virtues of single-case research, these features may also be a burden (Kvale, 1997). On the one hand, including too much detail and context may obscure the theoretical suggestions. On the other hand, "streamlining" the case requires that contextual details are taken out of the case and, as a result, may entail a risk of over-simplifying the case.

\section{Describing the process of the study}

The issue of selectivity concerns not only the communication of the case but also the communication of the casing process. As far as the casing process is concerned, the dilemma is in how much detail to account for the "dwindling road". How much context of the process should be included and how? In reality, "streamlined process accounts" given by some researchers, as if they have "managed" to hold on to the initial research ideas, are more of an abdication to mainstream positivistic research traditions than useful accounts of how the research was actually carried out. On the other hand, too much detail including all kinds of fruitless efforts and not-so-useful data, which are natural parts of the casing process, do not contribute to convincing any reader of the validity of the process and the results of the research.

Moreover, beginnings and endings of process-based singlecase research, i.e. setting boundaries around case studies in time, are problematic to combine with the casing logic as the processes that are subject to scrutiny do not end (Dubois and Gadde, 2002; Halinen and Törnroos, 2005). However, this has to do with complexity (of the open-ended processes subject to study) and with learning (in the process of study) and therefore concerns challenges that should not be ignored but embraced. Empirical and theoretical grounding, both salient features of single-case studies, and the matching of theory and empirical observation in the process of the study, relate to this dilemma. In view of these challenges, an important question is "How can single-case researchers account for the casing in their research process?" Others have pointed to strategies of going with the "mysteries" as they unravel or suggested that researchers should simply live with the messiness of being unable to match theory and cases ex ante (Flyvbjerg, 2006; Alvesson and 
Kärreman, 2007). However, while these strategies provide guidance to cope with complexity as it emerges, they deal less with how the process of learning unfolds, as case researchers traverse and sometimes get lost or find themselves in a context which stubbornly defies their initial assumptions. The latter requires process description and ex post argumentation for the rationales involved in the way the study was carried out. How this is done is a key issue to convince readers that the case, and the theory developed based on the single case, is grounded in both the theoretical and empirical domains.

Hence, it is a challenge to convey the casing process to the readers of case-based journal papers. To do justice to the process of single-case research, the method needs description in its own right. As discussed, the starting point, articulated as initial research ideas for a single-case study, may not be of particular interest or relevance to the reader of the eventual case, although the description of the research process as such is of importance. Identifying and explaining crucial choices made during the research process is one way of ensuring transparency of the research (Dubois and Gibbert, 2010; Gibbert and Ruigrok, 2010). "Openness" with regard to the interaction between theory and empirical observation should contribute to convince the reader of the theoretical and empirical grounding of the case study; "the intellectual journey needs description and reflection" (Dubois and Araujo, 2007, p. 178).

Piekkari et al. (2010), stressing the importance of reflexivity in reporting the methodological aspects of a case study, point to the problem of conventions when case-based research is concerned and how these conventions do not fit with casing processes in single-case studies. For instance, the numbers of interviews and interviewees are often described in detailed while the process of "finding" them is not accounted for. In case-based research published in top-tier marketing journals, it is not uncommon to find data accounts, which in terms of the number of interviews or observations (and other sources of data collected) can measure up to the sample sizes found in quantitative studies (Peñaloza, 2000). The focus on the volume of data links back to quantitative research norms, where tests of significance call for large amounts of data. However, it has to be borne in mind that the intended product of case-based research is to develop new insights, not to provide statistical tests of these insights (Flyvbjerg, 2006; Eisenhardt, 1989). While data richness can be an important provider of detail and a source of inspiration, the amount of data does not in itself provide better insights (Sutton, 1997). The quality of insights depends less on the volume of data than on the rigor of the analytical process carried out by the researcher (Weick, 1979). It can therefore be argued that the "analytical journey" of the researcher in the process of matching empirical data with theoretical ideas is of greater importance than the amount of data. Developing accounts for that process is a difficult but vital issue for the single-case researcher to deal with. Being able to trace the analytical journey of a researcher in terms of how data collection has spurred insights and how these have deepened, or have initiated a change in questioning, or the type of interviewee or data collected, provides insight into the process of "finding". Take as an example a B2B study of buying behavior in CERN (Aberg, 2013, p. 91):

In addition to the interviews made at CERN, a large number of informal discussions have been held there, since I have had the privilege of living and working at CERN during three extended visits. This means that I have had the opportunity to meet people informally [.] Moreover, I have had the possibility to participate in lectures and company presentations given at CERN. This has greatly contributed to my understanding of CERN as an organisation, but also of what it is like to work in this environment. It has also helped me understand a little bit of the frustration some Swedish companies have expressed during the interviews; that CERN is a complex place, and that "getting in" can be tricky.

Being able to follow more closely how different situations and how new insights changed the search for data provides transparency to process validation. The way great amounts of qualitative data are handled (see, for instance, Kvale 1997) concerns which parts to choose and how to frame them theoretically. However, genuinely surprising and inspiring insights may also come to the fore when researchers are not actively searching for data. Hence, detailed and meticulous scrutiny (March et al., 1991) may be combined with "sidekicks" when engaging in informal conversations or doing something else, perhaps in the vicinity of but not directly related to the case study (Sutton, 1997). Hence, the number of data sources conveys only a limited description of how the study was carried out and needs to be supplemented with descriptions of what data were used and how these were obtained and processed. The way the interviewees were found and the input from each interview led to the next may be of even greater importance when describing the casing process to an audience (Kvale, 1997). In addition, the way theoretical ideas evolved during these processes needs integration into the account to explicate how theory played roles of both input to and output from the casing process.

\section{Concluding discussion}

The paper has presented an argument for strengthening the standing of process-based single-case research in business marketing and highlighted particular process issues with respect to producing "good" single-case research. Validity claims can either be ignored on the basis that the validity concept is inherited from traditional positivistic research ideals (see, for instance, Creswell, 1998; Lincoln and Guba, 1985) or can be developed and used as a term for how well a single-case study has coped with matching theory to empirical observation, which is the perspective sided with here (Anderson and Herr, 1999; Kvale, 1997). However, this matching, and the process through which it is achieved, is associated with particular challenges for single-case researchers. Process validation is therefore suggested as a concept for the assessment of how well a process-based single-case study copes with these challenges. The paper has identified three specific issues that process-based single-case researchers always have to deal with: arbitrariness, richness and messiness. These issues are interrelated and concern the casing as such, the communication of the case to an audience and the description of how the process-based singlecase study is carried out. Table II summarizes these issues and the related dilemmas that the researcher needs to handle and points to key references and exemplars.

The three related dilemmas among the contradicting concerns all emanate from the process features of making a process-based single-case study, i.e. the actual casing. While this process is characterized by the researcher's interaction with theory and empirical "subjects", the interaction with other researchers, including reviewers, takes on additional 
Table II Three dilemmas and their characteristics

\begin{tabular}{|c|c|c|c|c|}
\hline Balancing acts & Issue/challenge & Dilemmas between & Key references & Exemplars \\
\hline $\begin{array}{l}\text { Crafting the } \\
\text { case - casing }\end{array}$ & Arbitrariness & $\begin{array}{l}\text { Settling too early in a premature lock-in situation } \\
\text { Continuing too far - ending up on an endless data } \\
\text { ride }\end{array}$ & $\begin{array}{l}\text { Ragin (1992) } \\
\text { Dubois and Gadde (2002) } \\
\text { Halinen and Törnroos (2005) } \\
\text { Easton (2010) } \\
\text { Michailova et al. (2014) }\end{array}$ & $\begin{array}{l}\text { Corsaro (2014) } \\
\text { Lüscher and Lewis (2008) }\end{array}$ \\
\hline $\begin{array}{l}\text { Communicating } \\
\text { the case }\end{array}$ & Richness & $\begin{array}{l}\text { Including too long and detailed descriptions that risk } \\
\text { obscuring theoretical contributions } \\
\text { Too concise and structured cases risking over- } \\
\text { simplification and lack of context }\end{array}$ & $\begin{array}{l}\text { Dyer and Wilkins (1991) } \\
\text { Easton (1995) } \\
\text { Gummesson (2003) } \\
\text { Starbuck }(2003) \\
\text { Flyvbjerg }(2006) \\
\text { Pratt }(2008,2009)\end{array}$ & $\begin{array}{l}\text { Kjellberg and Helgesson } \\
(2006) \\
\text { Peñaloza (2000) }\end{array}$ \\
\hline $\begin{array}{l}\text { Describing the } \\
\text { process of the } \\
\text { study }\end{array}$ & Messiness & $\begin{array}{l}\text { Including too much detail of the process, as well as } \\
\text { the abandoned routes } \\
\text { Too streamlined ex post rationalization of how the } \\
\text { study proceeded }\end{array}$ & $\begin{array}{l}\text { Sutton (1997) } \\
\text { Piekkari et al. (2010) } \\
\text { Alvesson and Sandberg (2011) } \\
\text { Dubois and Gadde (2014) }\end{array}$ & $\begin{array}{l}\text { Mariani (2016) } \\
\text { Wu et al. (2016) }\end{array}$ \\
\hline
\end{tabular}

challenges. Under the "right" conditions, this interaction contributes to improving the research quality as the single-case researcher's understanding of the research subject and relevant theoretical perspectives depend on interaction. The researcher's interaction with other researchers and anonymous reviewers may thus contribute "the distance" required to single out and present theoretical ideas, including how much and which empirical data to select to convey them. However, there is also potential in advancing the method semantics and general understanding of the different ways to conduct case research. Great amounts of data, interviews or cases do not guarantee great research, neither do streamlined ex post rationalizations or linear accounts of messy processes.

Rather, the inherent potentials in process-based single-case research reside in how it may unearth and thereby provide new perspectives for those acting in the reality studied. In its turn, it may change or develop the understanding of real-world processes of those governing or in other ways being subjected to some part in it, as well as to the research communities' ability to make sense of what happens. As pointed out by Gummesson (2014), there is a small step between the processes conveyed in these approaches and the works of a change agent seeking to solve particular problems: "the goals of academia and practice are partially different. What unites them is hopefully a desire to analyse and understand a situation develop it and find solutions to problems (Gummesson, op cit, p. 621).

Ideally, the quality of process-based single-case research is the ability of an unfolding reality to shape research designs rather than the other way around, as the researcher traverses into the empirical domain and learns from the process(es) he or she studies: never missing a beat, not hesitating or stopping the process of understanding what is really going on, because reality escapes predefined theoretical frameworks or data collection designs. Process-based single-case studies must allow researchers to grasp and convey central elements of the meaning-creating activities of actors in context and help us understand the world from the perspective of those living in it. In the presented view, a unique quality of process-based singlecase research is precisely the ability to follow suit to the beats in the empirical domain. This is a quality that it does not share with any other research strategy, including multiple-case designs, which have comparisons in relation to predefined issues as their priority. Single cases do not surface and present themselves to researchers in a cut-and-dried fashion. Rather, they are actively recognized and theoretically framed by researchers. However, they may also be hard to bring to the light and attention of the research community, which may be susceptible to their validity claims. They may lead to endless data rides and are frustrating in their unwillingness to bend into initial ideas of relevant theoretical concepts, what data to collect, etc. The dilemmas suggested in this paper may inspire reflective validation as researchers engage with process-based single-case studies. The notion of process validation may also support reviewers seeking to avoid missing out on, and instead contributing to, truly insightful case stories.

For reviewers, who see their task as helping authors to develop better manuscripts through constructive criticism, there are potential insights from the identified dilemmas on how to proceed effectively in review processes. First, in relation to crafting the case, reviewers may help authors to develop their manuscripts by asking them questions with respect to the effectiveness of their casing and also by asking questions that can support clarification of the suggested matches between case and theory. Second, given that narratives are central for conveying complex chains of events, reviewers may question the effectiveness of the narration of the manuscript and to what extent it delivers a narrative to which the reviewers (and with them the readers of the journal) can relate (Pollock and Bono, 2013). Finally, reviewers need to scrutinize and question the data journey as portrayed in the manuscript - this includes not only the descriptive account but also how and why the authors have been surprised and/or have made explicit choices throughout their research journey and how this has impacted on their casing.

As authors of this paper we have drawn on our experiences as case researchers in business marketing, and we believe they can be transferred to other specializations in business research. Although business marketing research has a distinct history and has co-evolved with the marketing field, other fields in which the interest in processes of various kinds are strong or growing, 
i.e. strategy, management and organization, share evolutionary traits and theoretical influences and, not least, methodological challenges. Where development of business marketing research is concerned, the increasing gamut of methodological approaches needs to go hand in hand with the enhancement of the specific features of each of these approaches. Shared interests in business marketing phenomena combined with respect for the specifics and strengths of the various methodological approaches applied will benefit the general advancement of the field.

\section{Note}

1 Multiple process-based case studies provide additional challenges with respect to how replication and comparison impact on validation processes, which is not discussed in the present context.

\section{References}

Aberg, S. (2013), Science in Business Interaction: A Study of the Collaboration Between CERN and Swedish Companies, Doctoral dissertation, Företagsekonomiska institutionen, Uppsala universitet.

Alvesson, M. and Kärreman, D. (2007), "Constructing mystery: empirical matters in theory development", Academy of Management Review, Vol. 32 No. 4, pp. 1265-1281.

Andersen, P.H. and Kragh, H. (2010), "Sense and sensibility: two approaches for using existing theory in theory-building qualitative research", Industrial Marketing Management, Vol. 39 No. 1, pp. 49-55.

Andersen, P.H. and Skaates, A.M. (2004), "Ensuring validity in qualitative international business research", in Piekkari, R. and Welch, C., (Eds), Handbook of Qualitative Research Methods for International Business, Edward Elgar Publishing, Vol. 23.

Anderson, G. and Herr, K. (1999), "The new paradigm wars: is there room for rigorous practitioner knowledge in schools and universities?", Educational Researcher, Vol. 28 No. 5, pp. 12-21.

Bansal, P. and Corey, K. (2012), "Publishing in AMJ - part 7: what's different about qualitative research?", Academy of Management Fournal, Vol. 55 No. 3, pp. 509-513.

Beverland, M. and Lindgreen, A. (2010), "What makes a good case study? A positivist review of qualitative case research published in industrial marketing management, 1971-2006", Industrial Marketing Management, Vol. 39 No. 1, pp. 56-63.

Bizzi, L. and Langley, A. (2012), "Studying processes in and around networks", Industrial Marketing Management, Vol. 41 No. 2, pp. 224-234.

Bonoma, T.V. (1985), "Case research in marketing: opportunities, problems and a process", fournal of Marketing Research, Vol. 22 No. 2, pp. 199-208.

Brinberg, D. and McGrath, J.E. (1985), Validity and the Research Process, SAGE Publications, Newbury Park.

Campbell, D.T. (1975), "III."Degrees of freedom" and the case study", Comparative Political Studies, Vol. 8 No. 2, pp. 178-193.

Corley, K.G. and Gioia, D.A. (2011), "Building theory about theory building: what constitutes a theoretical contribution?", Academy of Management Review, Vol. 36 No. 1, pp. 12-32.

Corsaro, D. (2014), "The emergent role of value representation in managing business relationships", Industrial Marketing Management, Vol. 43 No. 6, pp. 985-995.

Creswell, J. (1998), Qualitative Inquiry and Research Design: Choosing Among Five Traditions, Sage, Thousand Oaks, CA.

Davis, M.S. (1971), “That's interesting! towards a phenomenology of sociology and a sociology of phenomenology", Philosophy and Social Science, Vol. 1 No. 2, pp. 309-344.

Dubois, A. and Araujo, L. (2004), "Research methods in industrial marketing studies”, in Håkansson, H., Harrison, D. and Waluszewski, A. (Eds), Rethinking Marketing: Developing a New Understanding of Markets, John Wiley \& Sons, pp. 207-227.

Dubois, A. and Araujo, L. (2007), "Case research in purchasing and supply management: opportunities and challenges", fournal of Purchasing and Supply Management, Vol. 13 No. 3, pp. 170-181.

Dubois, A. and Gadde, L.E. (2002), "Systematic combining: an abductive approach to case research", fournal of Business Research, Vol. 55 No. 7, pp. 553-560.

Dubois, A. and Gadde, L.E. (2014), "Systematic combining a decade later", fournal of Business Research, Vol. 67 No. 6, pp. 1277-1284.

Dubois, A. and Gibbert, M. (2010), "From complexity to transparency: managing the interplay between theory, method and empirical phenomena in IMM case studies", Industrial Marketing Management, Vol. 39 No. 1, pp. 129-136.

Dyer, W.G. and Wilkins, A.L. (1991), "Better stories, not better constructs, to generate better theory: a rejoinder to eisenhardt", Academy of Management Review, Vol. 16 No. 3, pp. 613-619.

East, R. (2016), "Bias in the evaluation of research methods", Marketing Theory, Vol. 16 No. 2, pp. 219-231.

Easton, G. (1995), "Case research as a methodology for industrial networks: a realist apologia", in IMP Conference, 11 th ed., Vol. 11, IMP.

Easton, G. (2010), "Critical realism in case study research", Industrial Marketing Management, Vol. 39 No. 1, pp. 118-128.

Eisenhardt, K.M. (1989), "Building theories from case study research", Academy of Management Review, Vol. 14 No. 4, pp. 532-550.

Faes, W. and Matthyssens, P. (2009), "Insight into the process of changing sourcing strategies", fournal of Business $\mathcal{F}$ Industrial Marketing, Vol. 24 Nos 3/4, pp. 245-255.

Flyvbjerg, B. (2006), "Five misunderstandings about casestudy research", Qualitative Inquiry, Vol. 12 No. 2, pp. 219-245.

Gibbert, M. and Ruigrok, W. (2010), "The "what" and "how" of case study rigor: three strategies based on published work", Organizational Research Methods, Vol. 13 No. 4, pp. 710-737.

Giesler, M. and Thompson, C.J. (2016), "A tutorial in consumer research: process theorization in cultural consumer research", fournal of Consumer Research, Vol. 43 No. 4, pp. 497-508. 
Glaser, B. and Strauss, A. (1967), The Discovery of Grounded Theory: Strategies for Qualitative Research, Wiedenfeld and Nicholson, London.

Guenzi, P. and Storbacka, K. (2015), "The organizational implications of implementing key account management: a case-based examination", Industrial Marketing Management, Vol. 45 No. 2, pp. 84-97.

Gummesson, E. (2001), "Are current research approaches in marketing leading us astray?", Marketing Theory, Vol. 1 No. 1, pp. 4-25.

Gummesson, E. (2003), "All research is interpretive!", fournal of Business E Industrial Marketing, Vol. 18 Nos. 6/7, pp. 482-492.

Gummesson, E. (2014), "The theory/practice gap in B2B marketing: reflections and search for solutions", fournal of Business E Industrial Marketing, Vol. 29 Nos 7/8, pp. 619-625.

Halinen, A. and Törnroos, J.Å. (2005), "Using case methods in the study of contemporary business networks", fournal of Business Research, Vol. 58 No. 9, pp. 1285-1297.

Halinen, A., Medlin, C.J. and Törnroos, J.Å. (2012), "Time and process in business network research", Industrial Marketing Management, Vol. 41 No. 2, pp. 215-223.

Halinen, A., Törnroos, J.Å. and Elo, M. (2013), "Network process analysis: an event-based approach to study business network dynamics", Industrial Marketing Management, Vol. 42 No. 8, pp. 1213-1222.

Healy, M. and Perry, C. (2000), "Comprehensive criteria to judge validity and reliability of qualitative research within the realism paradigm", Qualitative Market Research: An International fournal, Vol. 3 No. 3, pp. 118-126.

Ketokivi, M. and Mantere, S. (2010), "Two strategies for inductive reasoning in organizational research", Academy of Management Review, Vol. 35 No. 2, pp. 315-333.

Kjellberg, H. and Helgesson, C.F. (2006), "Multiple versions of markets: multiplicity and performativity in market practice", Industrial Marketing Management, Vol. 35 No. 7, pp. 839-855.

Kvale, S. (1997), Den kvalitativa forskningsintervjun, Studentlitteratur, Lund.

Kwan, K.M. and Tsang, E.W. (2001), "Realism and constructivism in strategy research: a critical realist response to Mir and Watson", Strategic Management Fournal, Vol. 22 No. 12, pp. 1163-1168.

Langley, A. (1999), "Strategies for theorizing from process data", Academy of Management Review, Vol. 24 No. 4, pp. 691-710.

Langley, A., Smallman, C., Tsoukas, H. and Van de Ven, A.H. (2013), "Process studies of change in organization and management: unveiling temporality, activity and flow", Academy of Management fournal, Vol. 56 No. 1, pp. 1-13.

Lincoln, Y.S. and Guba, E.G. (1985), Naturalistic Inquiry, Sage, Beverly Hills, CA.

Lind, F. (2015), "Goal diversity and resource development in an inter-organisational project", fournal of Business $\mathcal{E}$ Industrial Marketing, Vol. 30 Nos 3/4, pp. 259-268.

Lüscher, L.S. and Lewis, M.W. (2008), "Organizational change and managerial sensemaking: working through paradox", Academy of Management foumal, Vol. 51 No. 2, pp. 221-240.

March, J.G., Sproull, L.S. and Tamuz, M. (1991), "Learning from samples of one or fewer", Organization Science, Vol. 2 No. 1, pp. 1-13.
Mariani, M.M. (2016), "Coordination in inter-network coopetitition: evidence from the tourism sector", Industrial Marketing Management, Vol. 53, pp. 103-123.

Marvasti, A.B. (2013), "Analysing observations", in Flick, U (Ed.), The SAGE Handbook of Qualitative Analysis, SAGE publications.

Medlin, C.J. (2004), "Interaction in business relationships: a time perspective", Industrial Marketing Management, Vol. 33 No. 3, pp. 185-193.

Michailova, M., Piekkari, R., Plakoyiannaki, E., Ritvala, T., Michailova, I. and Salmi, A. (2014), "Breaking the silence about exiting fieldwork: a relational approach and its implications for theorizing", Academy of Management Review, Vol. 39 No. 2, pp. 138-161.

Mintzberg, H. (2005), "Developing theory about theory development", in Smith, K.G. and Hitt, M.A. (Eds), Great Minds in Management: The Process of Theory Development, Oxford University Press.

Mishler, E. (1990), "Validation in inquiry-guided research: the role of exemplars in narrative studies", Harvard Educational Review, Vol. 60 No. 4, pp. 415-443.

Mohr, L.B. (1982), Explaning Organizational Behavior, JosseyBass, San Francisco.

Morgan, G. (1983), "Toward a more reflective social science". in Morgan, G. (Ed.), Beyond Method, Sage, pp. 368-376.

Munksgaard, K.B. (2015), "Is this network for you or for me? The pursuit of self and collective interests in a strategic network", Fournal of Business $\mathcal{E}$ Industrial Marketing, Vol. 30 Nos 3/4, pp. 279-289.

Nicholson, J.D., Brennan, R. and Midgley, G. (2014), "Gaining access to agency and structure in industrial marketing theory: a critical pluralist approach", Marketing Theory, Vol. 14 No. 4, pp. 395-416.

Peñaloza, L. (2000), "The commodification of the American West: marketers' production of cultural meanings at the trade show", Fournal of Marketing, October, Vol. 64 No. 4, pp. 82-109.

Perna, A., Baraldi, E. and Waluszewski, A. (2015), "Is the value created necessarily associated with money? On the connections between an innovation process and its monetary dimension: the case of Solibro's thin-film solar cells", Industrial Marketing Management, Vol. 46, pp. 108-121.

Perry, C. (1998), "Processes of a case study methodology for postgraduate research in marketing", European fournal of Marketing, Vol. 32 Nos 9/10, pp. 785-802.

Perry, C. (2000), "Case research in marketing", The Marketing Review, Vol. 1 No. 3, pp. 303-323.

Piekkari, R., Plakoyiannaki, E. and Welch, C. (2010), "Good” case research in industrial marketing: insights from research practice", Industrial Marketing Management, Vol. 39 No. 1, pp. 109-117.

Piekkari, R., Welch, C. and Paavilainen, E. (2009), "The case study as a disciplinary convention, evidence from international business journals", Organizational Research Methods, Vol. 12 No. 3, pp. 567-589.

Pollock, T.G. and Bono, J.E. (2013), "Being scheherazade: the importance of storytelling in academic writing", Academy of Management fournal, Vol. 56 No. 3, pp. 629-634.

Pratt, M.G. (2008), "Fitting oval pegs into round holes: tensions in evaluating and publishing qualitative research in top-tier North American journals", Organizational Research Methods, Vol. 11 No. 3, pp. 481-509. 
Pratt, M.G. (2009), "From the editors: for the lack of a boilerplate: tips on writing up (and reviewing) qualitative research", Academy of Management fournal, Vol. 52 No. 5, pp. 856-862.

Ragin, C.C. (1992), "Casing" and the process of social inquiry", in Ragin, C.C. and Becker, H.S. (Eds), What is a Case? Exploring the Foundations of Social Inquiry, Cambridge university press.

Riege, A.M. (2003), "Validity and reliability tests in case study research: a literature review with 'hands-on' applications for each research phase", Qualitative Market Research: An International fournal, Vol. 6 No. 2, pp. 75-86.

Ryan, A., Tähtinen, J., Vanharanta, M. and Mainela, T. (2012), "Putting critical realism to work in the study of business relationship processes", Industrial Marketing Management, Vol. 41 No. 2, pp. 300-311.

Silverman, D. (2000), "Analyzing talk and text", in Denzin, N.K. and Linclon, Y.S. (Eds), The Sage Handbook of Qualitative Research, Sage publications, Thousand Oaks, California.

Starbuck, W.H. (2003), "Turning lemons into lemonade: where is the value in peer reviews?", fournal of Management Inquiry, Vol. 12 No. 4, pp. 344-351.

Storbacka, K. and Nenonen, S. (2015), "Learning with the market: facilitating market innovation", Industrial Marketing Management, Vol. 44, pp. 73-82.

Sutton, R.I. (1997), "The virtues of closet qualitative research”, Organization Science, Vol. 8 No. 1, pp. 97-106.
Tähtinen, J. and Vaaland, T.I. (2006), "Business relationships facing the end: why restore them? ", Fournal of Business $\mathcal{E}$ Industrial Marketing, Vol. 21 No. 1, pp. 14-23.

Tsoukas, H. (1989), "The validity of idiographic research explanations", Academy of Management Review, Vol. 14 No. 4, pp. 551-561.

Tsoukas, H. (2005), "Afterword: why language matters in the analysis of organizational change", fournal of Organizational Change Management, Vol. 18 No. 1, pp. 96-104.

Van de Ven, A.H. (2007), Engaged Scholarship: A Guide for Organizational and Social Research, Oxford University Press, Oxford.

Van de Ven, A.H. and Poole, M.S. (2005), "Alternative approaches for studying organizational change", Organization Studies, Vol. 26 No. 9, pp. 1377-1404.

Weick, K.E. (1979), The Social Psychology of Organizing, 2nd ed., Reading MA.

Wu, A.Y.H., Little, V.J. and Low, B. (2016), "Inbound open innovation for pharmaceutical markets: a case study of an anti-diabetic drug in-licensing decision", fournal of Business E Industrial Marketing, Vol. 31 No. 2, pp. 205-218.

Yin, R.K. (2014), Case Study Research: Design and Methods, 5th ed., Sage Publication.

\section{Corresponding author}

Poul Houman Andersen can be contacted at: poa@ business.aau.dk 